Wilfrid Laurier University

Scholars Commons @ Laurier

1999

\title{
Enhanced Reproductive Success of Female Black-Capped Chickadees Mated to High-Ranking Males
}

\author{
Ken A. Otter \\ Queen's University -- Kingston
}

Scott M. Ramsay

Wilfrid Laurier University, sramsay@wlu.ca

Laurene M. Ratcliffe

Queen's University -- Kingston

Follow this and additional works at: https://scholars.wlu.ca/biol_faculty

\section{Recommended Citation}

Otter, Ken A.; Ramsay, Scott M.; and Ratcliffe, Laurene M., "Enhanced Reproductive Success of Female Black-Capped Chickadees Mated to High-Ranking Males" (1999). Biology Faculty Publications. 34. https://scholars.wlu.ca/biol_faculty/34 accepted for inclusion in Biology Faculty Publications by an authorized administrator of Scholars Commons @ Laurier. For more information, please contact scholarscommons@wlu.ca. 


\title{
ENHANCED REPRODUCTIVE SUCCESS OF FEMALE BLACK-CAPPED CHICKADEES MATED TO HIGH-RANKING MALES
}

\author{
Ken O'Tler, ${ }^{1}$ SCOI'l M. Ramsay, and Laurene Ratclithe \\ Department of Biology, Queen's University, Kingston, Ontario K7L 3N6, Canada
}

\begin{abstract}
Overwinter survival of female Black-capped Chickadees (Poecile atricapillus) depends in part on the rank of their mates. We investigated whether females also gain reproductive benefits by pairing with high-ranking males. We assessed breeding success in 1993 to 1995 and 1997 by comparing clutch size, proportion of eggs hatched, hatching date, and predation rates on nests of females mated to either high-ranking or low-ranking males. We also compared feeding rates of males to incubating females and to offspring during the early nestling periud in 1994 and 1995. Hight-ranking and luw-ranking males did not differ in feeding rates during early incubation or early nestling stages. Females mated to highranking males incubated for longer periods than females mated to low-ranking males. Younger males and females mated to low-ranking males fed nestlings at a higher rate than did older males and females mated to high-ranking males, respectively. Females mated to highranking males had larger clutches, hatched a significantly greater proportion of their eggs, and suffered lower nest predation than females mated to low-ranking males. In 1995 and 1997, where the ranks and ages of both members of 23 pairs were known, female rank was strongly correlated with mate rank and age but was only weakly associated with female age. Female rank accounted for significant variation only in clutch size, and male rank accounted for a greater proportion of variation in clutch size and fledging success than did the female's own rank. Received 19 December 1997, accepted 13 July 1998.
\end{abstract}

RerkUnul HVe SULCESS IN FEMALE BiRUS IIIAy be limited by several factors. Density of the breeding population (Dhondt et al. 1990, Kempenaers and Dhondt 1992) as well as resource access and quality of the territory at the time of nest initiation can limit the number of eggs a female produces (Högstedt 1980; Nur 1984a, 1986; Smith 1991; Dhondt et al. 1992). Females may also be limited by the number of young they can provision (Trivers 1972. Slagsvold and Lifjeld 1990) and their ability to avoid nest predation. Although a female's ability to produce and feed a large clutch is probably related to factors such as age, experience, and physical condition (Slagsvold and Lifjeld 1990), evidence for some species suggests that the female's access to resources necessary for breeding is influenced by the quality of her mate.

Because the onset of laying (Källander 1974, von Brömssen and Jansson 1980) and the ability to produce eggs (Nur 1986, Smith 1991) may be limited by food at the time of egg laying, females that pair with males that can acquire the most productive territories may have the high-

\footnotetext{
${ }^{1}$ Present address: Zoological Institute, University of Copenhagen, Tagensvej 16, DK-2200, Copenhagen N, Denmark. E-mail: kotter@zi.ku.dk
}

est reproductive success. Dhondt et al. (1992) found that clutch size in Blue Tits (Parus caeruleus) was related to territory quality. In both Blue Tits and Great Tits ( $($. major), average productivity of clutches among populations was directly related to territory quality in the breeding area (Dhondt et al. 1990). In nonmigratory species in the temperate zone, the nutritional condition of a female as she enters the hreeding seasnn likely is inflipenced hy her arcess to resources during the preceding winter as well as by the quality of the territory that her mate can secure in spring. Winter survival (Smith 1984, 1994) and access to winter resources (Lemmon et al. 1997) for female Blackcapped Chickadees (Poecile atricapillus) are more dependent on the rank of the female's mate than on her own rank within the flock. High-ranking pairs of Black-capped Chickadees appear to gain higher-quality breeding territories than do subordinate pairs (Smith 1991). Thus, females mated to high-ranking males gain access to better resources such as food and nest sites. The female's own quality probably will influence her ability to produce and provision offspring (Slagsvold and Lifjeld 1990). However, the protection in winter and the majority of territory defense in spring that 
allow access to the resources that limit clutch size in females are provided by the male (Smith 1991).

Male parental investment may also influence female reproductive success because male chickadees feed their mates during egg laying and incubation and perform most of the feeding visits to the nest during the first half of the nestling period (Smith 1991). Courtship feeding may not influence the ability of the female to produce a large clutch size as much as does territory quality (Kempenaers and Dhondt 1992), but male provisioning can affect a female's ability to incubate (possibly affecting the proportion of eggs that hatch; Slagsvold and Lifjeld 1990) and the survival of the offspring (Hill 1991). Slagsvold and Lifjeld (1990) found no significant reduction in the number of young fledged when provisioning by male Blue Tits was reduced through experimental "handicapping" (removal of several wing and tail feathers). In contrast, the number of young tledged decreased when females were handicapped. Slagsvold and Lifjeld (1990) concluded that male quality had less influence on reproductive success than did female quality. However, overall fledging success in the year of male handicapping was low compared with years of female handicapping. This may have influenced the ability to detect differences between handicapped and control males (fledging success was lower in both control and handicapped males than in the nests of handicapped females). Male handicapping appeared to affert the proportion of egge that hatched, suggesting that male provisioning, in addition to territory acquisition, influences female reproductive success. Thus, females mated to males who can secure territories richer in food and who are more attentive to provisioning the nest may have higher reproductive success than females mated to lower-quality males.

Female chickadees seek opportunities to pair with males that have a higher rank than their own mates (Otter and Ratcliffe 1996), suggesting that females gain additional reproductive benefits based on the relative rank of their mates. The aim of our study was to determine whether reproductive success in female Blackcapped Chickadees is influenced by the rank of their mates. We also investigated the effects of breeding experience (measured by age of the female and her mate) on female reproductive success. Using data from an ongoing study of chickadee mating behavior in Ontario, we monitored breeding pairs from 1993 to 1995 and in 1997, noting hatching date, clutch size, number of young produced, nesting success, and provisioning rate of males of different ranks. We assumed that offspring produced in the nest were the true genetic offspring of the female in assessing female reproductive success (confirmed by genetic analysis of nestlings in 58 nests sampled during the same period as this study; Otter et al. 1998).

\section{Study AREa And Methods}

Study area and dominance assessment.-The study was conducted at the Queen's University Biology Station located at Chaffey's Locks, $50 \mathrm{~km}$ north of Kingston, Ontario, where we have been monitoring a color-marked population of chickadees since 1988. The 150-ha study site is characterized by continuous deciduous forest interspersed with small fields. Territories of the birds are contiguous. Most birds were captured and banded in December and January in each year of the study. At initial capture in December, birds werc classificd as cither hatching ycar (HY) or after-hatching-year (AHY) based on the shape of their rectrices (Meigs et al. 1983). For simplicity, we continued to use these classifications throughout the winter rather than switch HY to second-year (SY) and AHY to after-second-year (ASY) at 1 January. Thus, " $\mathrm{HY}$ " designates birds entering their first winter up to first breeding season, and "AHY" designates birds entering their second (or later) winter and their second (or later) breeding season. Sex of birds was initially determined at the time of banding by a combination of body measurements (Desrochers 1990) and was confirmed by behavioral observations of individuals during the breeding season.

Dominance ranks were assessed by monitoring aggressive interactions between individually marked birds at winter feeders (see Ficken et al. 1990, Otter et al. 1994, 1997; Otter and Ratcliffe 1996). Fixed winter feeders (a 1.5-L bird feeder filled with sunflower seeds plus a suet feeder at each site) were established in December and maintained through February each year to maintain stable use by flocks. A linear dominance matrix was determined for each flock by tallying the outcome of aggressive interactions between birds. A bird was considered dominant to another individual if it won the majority of direct interactions with it. We confirmed our assessment of relative ranks by assessing each individual against birds of intermediate rank in inter-flock hierarchies. Dominance hierarchies were determined using approxi- 
mately 8,000 interactions witnessed in the four years of the study. An average of $5.0 \pm \mathrm{SE}$ of 3.5 interactions was seen between each dyad of birds in flocks, including male / female comparisons (male / male dyads had an average of $6.3 \pm 0.7$ wilnessed interactions/dyad). In most cases $(>80 \%)$, one member of the dyad won all witnessed interactions between the two focal birds. Flock hierarchies in our study population were linear, stable between years, and not site dependent (Otter et al. 1997).

Male rank was classified as either high (top-ranking inlale, includes 2nd-ranking males in flocks of four or more pairs) or low (2nd-ranking males in flocks of two pairs, 3rd-ranking male in flocks with three pairs. 4th-ranking and lower males in flocks of four or five pairs). These criteria, rather than classifying males by their absolute rank within their flock, take into account differences in the number of males within flocks (which ranged from two to five). Classifying the second-ranked male in a two-male flock as low ranking puts him in the same category as the 4th and 5th male in a five-male flock (rather than in the same category as the 2 nd male from a five-male flock). Because high-ranking individuals from one flock tend to also dominate low-ranking males from other flocks, this classitication approach likely is a biologically accurate categorization of relative ranks in males.

Female ranks were more difficult to discern, and sufficient data were available only for 1995 and 1997. Females were classified by interactions with other females in the flock, and individuals were deemed high or low ranking by the criteria used for males. Female ranks tend to be similar to the relative intrasexual rank of their mates (Otter and Ratcliffe 1996); however, discrepancics in the intrascxual ranks of members of a pair occur on occasion (see also Lemmon et al. 1997).

Nest location and feeding rates.-We located nests of territorial pairs during April through June of 1993 to 1995 and 1997. Feeding-rate data were collected at nests in 1994 and 1995. If a nest cavity was located during cxcavation or egg laying, we munitued the nest approximately every three days to determine the onset of incubation by direct observation into the cavity, by observing males feeding females, or by flushing incubating females. On the third day following confirmed incubation, we observed the nest for one hour to determine the amount of time the female spent inculating and the number of times she was fed by her mate. Three days later we observed the nest for another one-hour period. One of the two observations was conducted in the morning (ca. 0600 to 0700) and one in the afternoon (ca. 1300 to 1400), the sequence chosen using a randomized block design. If nests were located when the females had already begun to incubate, we conducted the first observation in the earliest observation period available and conducted the second observation three days later.
The sampling procedure of two one-hour observations separated by three days was chosen primarily to standardize observations between nests for time of day and stage of the nesting cycle. Preliminary observations at nine nests in 1993 showed that males usually made several feeding visits during each observation period, that the interval between feedings for a particular male was ennsistent within and between observations, and that conducting more observation periods did not result in differences in mean feeding rates (K. Otter, S. Rice, and L. Ratcliffe unpubl. data). Thus, two one-hour sampling periods appeared to adequately characterize the male contribution during this phase of nesting and allowed a higher number of nests to be sampled than if cach nest was observed on a larger number of sampling days. The primary objective of the feeding observations was to compare feeding effort among males rather than to track changes in provisioning rates of individual males throughout the nesting period (see Haftorn 1979). Toward this end, we strived to observe as many nests as possible during a restricted period of the nesting cycle.

We began watching nests 13 to 14 days after the start of incubation to confirm hatrhing The firct hour of observation of nestling feeding was conducted three to four days posthatching; a second hour of observation was conducted three days later. During the first half of the 16-day nestling period, the male is the primary provisioner of the nestlings, whereas the female either forages for herself or broods her nestlingo (Smith 1991). During this pcriod, male provisioning rates to nestlings may strongly influence the female's reproductive success, which is why we focused our observations on this stage of the nestling cycle. Observations were conducted in the same time periods used during incubation observations, and sequence was again chosen randomly. If nests were Iocated after the young had hatched, we conducted the first observation in the next available period. These latter nests were only included in the data if the first ohservation was onnducted on or before siv days posthatching. During each one-hour observation period, we recorded the number of times the adults brought food items to the nest and identified the individuals based on their leg bands. Identification of prey was not possible in all cases, although most of the prey items were caterpillars and spiders (similar to other studies; see Smith 1991).

Breeding success.-For nests in natural cavities, hatching date was confirmed by direct observation or by observation of changes in parental feeding behavior. Hatching dates estimated by changes in parental feeding behavior were confirmed by estimating ages of young when blood samples were collected at approximately seven days posthatching (range 6 to 13 days; Otter et al. 1998). Nestling development was compared with young of known age, and this tech- 
nique proved accurate to within approximately one day.

We checked for unhatched eggs (which usually are not removed by parents; Smith 1991) at the time of blood sampling. In nests that could not be observed directly until blood sampling, clutch sizes were determined by the number of nestlings plus the number of unltalchied egys. In tiests where cluld sice could be counted directly, clutch size always coincided with the number of nestlings and unhatched eggs. Nests were considered successful if at least one nestling survived to 14 days posthatching (fledging occurs at 16 to 17 days; Smith 1991). Where nests could not be reached, parental feeding was used as a gauge of nest activity on day 14 .

Four nests from 1993 and 18 nests from 1997 were added to the data from 1994 and 1995 for analysis on clutch size and hatching / fledging success to increase sample size. A small number of males and females nested in more than one year. Of the nests considered in the analyses, 50 males and 50 females bred in one year only, 13 males and 13 females bred in two of the four years, and 1 male and 1 female bred in three of the four years. Of the birds that bred in two or more years, only four pairs retained mates from a previous year: one pair's nest was depredated in both years, two pairs successfully fledged young in both years (one high-ranking and one low-ranking pair), and one pair successfully fledged young in one year but not in the other (high ranking). Because almost all females either bred once or with different males in two nesting attempts, and the few pairs that remained together did not have consistent fledging success, we considered each nesting attempt to be an independent event.

Analyses. -We assessed yearly variation in feeding rates and reproductive success with ANOVA. Nestling feeding rates by adults were standardized as the number of fecdo/ncotling in the clutch. Proportional data, such as the proportion of eggs laid that hatched, were arcsine square-root transformed.

The effects of age and rank on feeding rates and reproductive success were analyzed with stepwise multiple regression. This approach allows the four classification variables (male age, female age, male rank, and female rank) to be testcd simultancously for their influence on each dependent variable. Owing to the strong association between intrasexual ranking of mated pairs, male rank was used as a proximate measure of the rank of the pair. Thus, in the four-year data set the three classification variables were male age, female age, and male rank. Because female rank was known in the 1995 and 1997 data sets, the nesting success results were retested for nests in these two years with all four classification variables. This latter test allowed us to determine whether female rank versus male rank was more influential in nesting success.

Most chickadee nests were in natural cavities, al- though some nest boxes were used in each year. In 1994 , about half of the pairs (13/25 nests) nested in specially designed chickadee nest boxes (see Grubb and Bronson 1995), but in no other year did more than three pairs nest in boxes. To determine if nest boxes affected reproductive success, we assessed the difference between pairs nesting in either substrate during 1994. We found no difference betwecn pairs nesting in boxes versus natural cavities for clutch size $(t=1.32, \mathrm{df}=23, P=0.20)$, proportion of eggs that hatched $(t=-1.1, \mathrm{df}=23, P=0.28)$, and hatching date $(t=0.39, \mathrm{df}=23, P=0.70)$. Moreover, the probability that nestlings survived to fledging did not differ between nests in boxes $(12 / 13)$ and those in Ilditural cavities $(8 / 12$, Fishlier's exact lest, $P$ $0.16)$. Therefore, we combined artificial and natural cavities for analyses of clutch size and probability of fledging.

\section{RESULTS}

Annual variation in reproductive success and feeding rates.-Hatching date varied significantly among years $(F=5.80, \mathrm{df}=2$ and $62, P=$ 0.005; the four nests from 1993 were excluded from this analysis owing to lower confidence in exact hatching dates). Annual variation in clutch size approached significance $(F=2.61$, $\mathrm{df}=3$ and $54, P=0.06$ ), but the proportion of the eggs that hatched did not vary significantly among years $(F=0.23$, dt $=3$ and $52, \mu=0.87)$.

The rate at which males fed incubating females $(F=0.36, \mathrm{df}=1$ and $41, P=0.55)$ and nestlings during the early nestling period $(F=$ 2.6, $\mathrm{df}=1$ and 29, $P=0.12$ ) did not differ among years. However, the total time females spent on the nest during incubation differed among years $(F=4.39, \mathrm{df}=1$ and $41, P=0.04)$, as did the rate that females fed nestlings ( $F=$ $5.6, \mathrm{df}-1$ and $29, P=0.02)$. Where yearly variation was found (conservatively assessed as any difference between years where $P<0.1$ ), we standardized data by determining the average value of the variable (e.g. clutch size) for each year and then transforming the data as a deviation from the yearly average.

Age and rank among mated pairs.-A total of 23 pairs from 1995 and 1997, where the intrasexual ranks and ages of both members of the pair were known, were assessed for intercorrelations using a principal component analysis between age and rank (Table 1). Male age was strongly correlated with male rank, but female age was not as strongly correlated with female rank. Rather, the two highest correlates of fe- 
TABLE 1. Correlation matrix ( $r^{2}$ values) from a principal components analysis of male and female age and rank among 23 pairs of Black-capped Chickadees breeding in 1995 and 1997.

\begin{tabular}{lcccc}
\hline \hline & $\begin{array}{c}\text { Male } \\
\text { age }\end{array}$ & $\begin{array}{c}\text { Female } \\
\text { age }\end{array}$ & $\begin{array}{c}\text { Male } \\
\text { rank }\end{array}$ & $\begin{array}{c}\text { Female } \\
\text { rank }\end{array}$ \\
\hline Male age & - & -0.09 & 0.65 & 0.72 \\
Temale age & - & - & 0.12 & 0.20 \\
Male rank & - & - & - & 0.91 \\
\hline
\end{tabular}

male rank in intrasexual contests were with the rank and age of her mate (Table 1).

Feeding rates.-The number of times males fed their incubating mates was not significantly associated with male age, female age, or male rank (stepwise multiple regression; male age, $F$ $=0.21, P=0.65$; temale age, $F=2.80, P=0.10$; male rank, $F=0.26, P=0.61$; Table 2). However, females mated to high-ranking males spent more time in the cavity incubating during the two combined 1-hour watches than females mated to low-ranking males, but time spent incubating was not significantly affecled by male or female age (male age, $F=3.17, P=$ 0.09 ; female age, $F=0.30, P=0.59$; male rank, $F=4.08, P=0.05$; Table 2).

Nestling feeding rates by individual males did not differ significantly between the first and second observation periods (comparison between number of feeds in the first watch after hatching vs. the second watch two to three days later; paired $t$-test, $t=-1.54, \mathrm{df}=34, P=$ 0.13 ). There was also no difference in feeding rates between first and second watches when males were compared by age $(t=-0.24, \mathrm{df}=$ $32, P=0.41)$ or rank $(t=0.76, \mathrm{df}=25, P=0.23$; Fig. 1). However, feeding rates of individual females increased significantly between the first and second watches (paired $t=-2.46, \mathrm{dt}=34$, $P=0.02)$. This increase was attributable to female age; the increase in feeding rate between first and second watches was higher for $\mathrm{AHY}$ females than for HY females $(t=-2.4, \mathrm{df}=31$, $P=0.023$ ). Feeding rates by AHY females were significantly lower than those of HY females during the first watch $(t=2.30, \mathrm{df}=39, P=$ 0.014). During the second watch, however, AHY females tended to feed at higher rates than HY females, although not significantly $(t$ $=-1.53, \mathrm{df}=32, P=0.07)$. Rank of the female's mate did not influence her feeding rate in the first $(t=-0.39, \mathrm{df}=30, P=0.35)$ or second watch $(t=0.14, \mathrm{df}=25, P=0.44)$. Lower

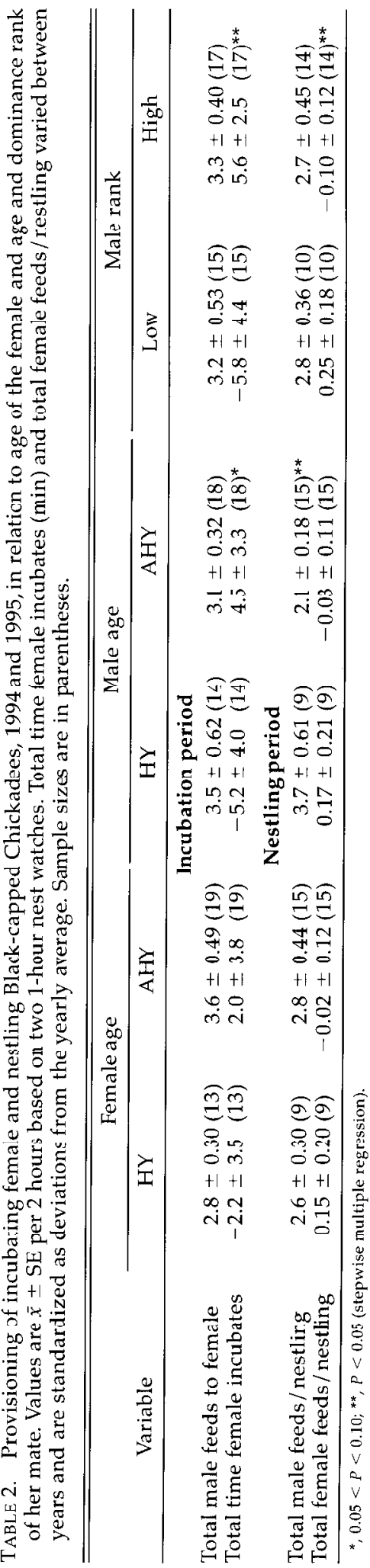




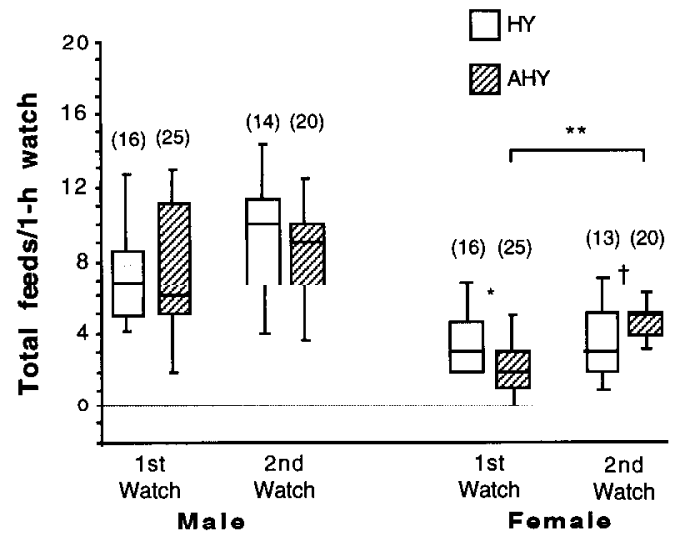

FIG. 1. Comparison of nestling feeding rates of Black-capped Chickadees during the first and second 1-hour watch periods by adult sex (paired $t$ test; $* *, P<0.05)$ and age $\left(t\right.$-test; ${ }^{*}, P<0.05 ; t, 0.05<P$ $<0.1), 1994$ and 1995. The first feeding watch was conducted 3 to 4 days posthatching, and the second 6 to 7 days posthatching. Boxplots show medians (horizontal lines), upper and lower quartiles (rectangles), and range (whiskers), with sample sizes in paientlieses ( $n-j 6$ itests lutal).

santele sizes in the secund watch in unpaired tests reflect nests lost to predation.

We combined the number of feedings in both 1 hour watches to compare overall feeding rates between males and females. Male age was the only significant variable that predicted nestling feeding rates hy the males, with $\mathrm{HY}$ males feeding more per nestling than did $\mathrm{AHY}$ males (male age, $F=6.92, P=0.017$; female age, $F=0.22, P=0.64$; male rank, $F=1.46, P$ $=0.24$; Table 2). Females mated to low-ranking males fed more per nestling than females mated to high-ranking males, but neither male age nor female age was significantly related to female feeding rates (male age, $F=0.04, P=$ 0.67 ; female age, $F=1.87, P=0.19$; male rank, $F=7.85, P=0.011$; Table 2 ).

Clutch size and probability of fledging.-We excluded three nests in 1995 from analyses of clutch size and number of young hatching. Two of these nests contained eggs from intraspecific brood parasitism (Otter et al. 1998); thus, the number of eggs in the nest did not represent the number that the parents were conditionally able to lay or anticipated to rear (56 of 58 nests assessed for parentage showed a genetic match between the social mother and all nestlings). The third nest had low hatching success ( 2 of 5
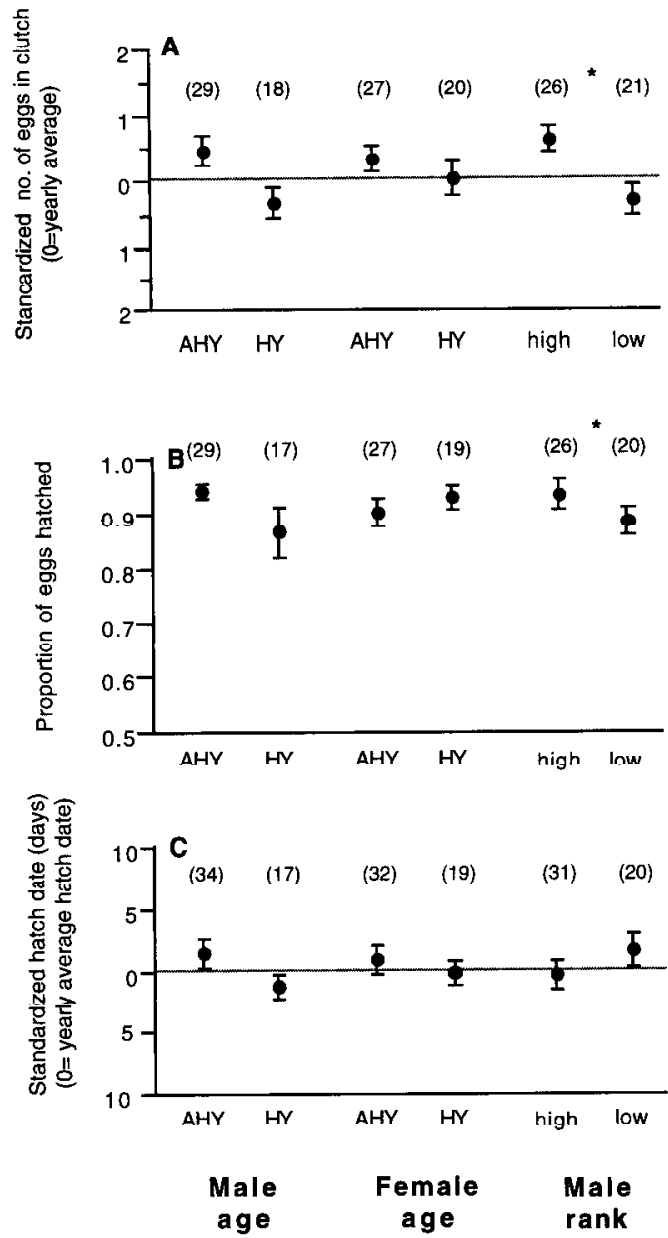

FIG. 2. Clutch size (A), proportion of eggs hatched (B), and standardized hatching date (C) of Black-capped Chickadee nests in 1993, 1994, 1995, and 1997 classified by male age, female age, and male rank. Influence of age and rank on each measure of reproductive success was determined by stepwise mulliple regression. $*, \Gamma<0.05$. Sample sizes are in parentheses.

eggs hatched) owing to accidental damage during our nest inspections.

Females mated to high-ranking males laid more eggs than females mated to luw-ranking males, but neither male age nor female age accounted for significant variation in the number of eggs laid (malc agc, $F=3.38, P-0.07$; female age, $F=0.115, P=0.74$; male rank, $F=$ $6.02, P=0.018$; Fig. 2A). To determine if increased clutch size in high-ranking pairs was attributable to the female's own rank versus that of her mate, we retested the 1995 and 1997 
data set to include female rank as a predictor of clutch size. Both female rank and male rank accounted for significant variation in clutch size, but the highest variation was attributed to the rank of the female's mate rather than her own rank (male age, $F=1.33, P=0.27$; female age, $\Gamma-0.03, P-0.06$; male rank, $F-14.80, P-$ 0.0023 ; female rank, $F=6.51, P=0.025$ ). The influence of female rank in these analyses is likely to be partially due to the strong inter correlation between ranks of mated pairs, but the stronger influence of male rank in these analyses siiggests that male rank rather than female rank is the more important factor influencing clutch size.

The proportion of eggs that hatched was higher for females mated to high-ranking males than for those mated to low-ranking males but was not significantly related to the age of the female's mate or the female's own age (male age, $F=0.74, P=0.39$; female age, $F=$ $0.04, P=0.83$; male rank, $F=4.96, P=0.031$; Fig. 2B). When the 1995 and 1997 data set including female ranks was tested, however, the effect of male rank was not significant, although male rank accounted for more of the variation in hatching success than did female rank (male age, $F=0.31, P=0.59$; female age, $F=0.02, P=0.90$; male rank, $F=3.00, P=$ 0.11; female rank, $F=0.67, P=0.43$ ).

Hatching date was not related to male age, female age, or miale rank in either the four-year data set (male age, $F=1.34, P=0.25$; female age, $F=0.43, P=0.51$; male rank, $F=0.66, P$ -0.42 ; Fig. 2C) or with the inclusion of female rank in the 1995/1997 data set (male age, $F=$ $1.53, P=0.23$; female age, $F=0.30, P=0.59$; male rank, $F=0.006, p-0.91$; female rank, $F$ $=0.08, P=0.78$ ).

Nestlings of females with high-ranking mates had a higher chance of surviving to fledging than did those of females with lowranking mates (Fisher's exact test, $P=0.025$; Table 3). Fledging success was not attributable to age of the female $(P=0.58)$ or to age of her mate $(P=1.0)$. Using only the data from the nests in 1995 and 1997 where female and male ranks and fledging success were known $(n=$ $22)$, the probability that nestlings fledged was not significantly related to female rank $(P=$ 0.10 ) but was significantly related to the rank of the female's mate ( $P=0.043)$, with nestlings from nests with a high-ranking male having
TABle 3. Survival of Black-capped Chickadee nestlings in 1993, 1994, 1995, and 1997. Values are number of nests where offspring survived to 14 days posthatching.

\begin{tabular}{|c|c|c|c|c|c|c|}
\hline \multirow[b]{2}{*}{ Outcome } & \multicolumn{2}{|c|}{ Male age } & \multicolumn{2}{|c|}{ Female age } & \multicolumn{2}{|c|}{ Male rank } \\
\hline & $\mathrm{HY}$ & $\mathrm{AHY}$ & $\mathrm{HY}$ & $\mathrm{AHY}$ & Low & High \\
\hline Fledge & 15 & 26 & 14 & 27 & 11 & 26 \\
\hline Did not fledge & 8 & 12 & 8 & 11 & 12 & 7 \\
\hline
\end{tabular}

higher probability of survival. Nesting failure was attributable primarily to predation by black rat snakes (Elaphe obsoleta), raccoons (Procyon lotor), red squirrels (Tamiasciurus hudsonicus), and eastern chipmunks (Tamias striatus). White-footed mice (Heromyscus leucopus), House Wrens (Troglodytes aedon), and flying squirrels (Glaucomys) spp. also usurped a small number of nests (two to four nests combined) of breeding chickadees each year. Nestlings in three nests during the study period died of exposurc or descrtion by parcnts.

\section{Discussion}

The ability of females to produce large clutches may reflect differences in territory quality at the time of egg formation and laying (Högstedt 1980, 1981; Nur 1986; Dhondt et al. 1992). Thus, one would predict that females mated to high-ranking males will enjoy better access to resources because such males appear able to acquire high-quality nesting territories (Smith 1991). Female chickadees mated to highranking males laid larger clutches, which may reflect the quality of the territory at time of egg laying. The number of eggs laid by females was more closely related to the rank ot her mate than to her own rank. Dhondt et al. (1992) found that occupation of low-quality territories by Blue Tils in ligh-density years was associated with lower clutch sizes of females in the low-quality territories. This may explain the pattern scen in chickadccs, because chickadees breed in most available areas in our study site, and supplemental feeding in winter may increase density of the breeding population (Smith 1991). Thus, it is likely that some lowranking pairs were only able to acquire poorquality territories that could have negatively affected the female's ability to produce eggs.

Females mated to high-ranking males hatched a larger proportion of their clutch, re- 
sulting in a higher number of young. These females may have been more successful because they spent a greater amount of time incubating. High-ranking males, however, did not feed their mates at higher rates than did low-ranking males. High-ranking males also did not feed nestlings at higher rates than low-ranking males during the early stages of the nestling period. This does not suggest, however, that imales do nol differ in the material resources that they can provide to their mates or nestlings. Much of the male contribution in chickadces likely comes from territory defense and the acquisition of resources to which females gain access. The ability to acquire a high-quality territory is likely to differ among males based on relative rank (Smith 1991) and may contribute to female condition and quality (as well as quantity) of food available to nestlings that could account for the differences in clutch sizes and nesting success that we observed. Lemmon et al. (1997) argued that much of a female's access to resources in winter flocks is more closely related to the rank of her mate than to her own absolute rank in winter flocks. Similarly, we found that female intrasexual rank in flocks is more closely correlated with the rank of her mate than with her own age, suggesting that females benefit by pairing with high-ranking males. Because female chickadees suffer less aggression and have higher access to winter resources owing to the protection provided by their mates (Lemmon et al. 1997), females mated to high-ranking males may enter the breeding season in betler condition than those mated to low-ranking males. Territories of high-ranking males may have more food than those of low-ranking males, or females mated to high-ranking males may contribute less to territory defense than females mated to low ranking males, either of which would provide females with more time to forage during the prelaying period. These factors, which affect the ability of female chickadees to lay large clutches, currently are being investigated.

Females mated to high-ranking males have a higher likelihood of raising their nestlings to fledging than do females mated to low-ranking males. Among a smaller subset of the data where female and male ranks within pairs were known, fledging success was only attributable to male rank. Neither clutch size, proportion of eggs that hatch, nor fledging success was dependent on the age of the female or her mate (a measure of previous breeding experience). Thus, the reproductive success of females appears to be improved by mating with high-ranking males, which may explain the willingness of females to desert their current breeding partner if Indes or higher rank vecome available (Otter and Ratcliffe 1996).

Several potential problems have been proposed that counter the notion that femalcs lay ing large clutches are at a reproductive advantage: (1) larger clutches may impose greater feeding costs on parents, reducing their own rate of survival (Lack 1954; Nur 1984a, 1988); (2) larger clutches may result in fewer feedings per nestling. lower body mass at fledging, and lower survival prospects for nestlings (Nur 1984b, 1988; Gustafsson and Sutherland 1988; Orell and Koivula 1988); and (3) larger clutches (and thus brood sizes) may increase the probability of predation owing to increased noise levels at the nest (Perrins and Moss 1975; Nur $1984 \mathrm{~b}$ ). Several lines of evidence suggest that these conditions do not affect recruitment of chickadee young.

If survival of parents is reduced in pairs that rear large clutches, then the birds with the largest number of young in their nests (i.e. highranking pairs) should have the highest mortality rates. However, survival is positively correlated with rank in chickadees, and the probability of female survival increases with the increasing rank of her mate (Smith 1984, 1994). Willow Tit (Parus montanus; Orell and Koivula 1988), Gieal Til (Perrins and Moss 1975), and Black-billed Magpie (Pica pica; Högstedt 1980, 1981) pairs with the highest natural clutch sizes also show the highest probability of survival to future breeding. Thus, adults at nests that naturally produce the most young do not necessarily have the highest mortality rates.

Because begging vocalizations may attract predators, it has been suggested that large clutches might increase the likelihnod of nest predation (Perrins and Moss 1975). However, females mated to high-ranking males in our study produced more young and were the least likely to have their nests depredated, which does not support the begging vocalization/ predation-risk hypothesis. Nesting success may be related more to nest height than to the amount of nestling begging, as suggested for Carolina Chickadees (Poecile carolinensis; Alba- 
no 1992). At present, we are comparing differences in availability of high-quality nest sites within the territories of high-ranking and lowranking males to determine the causal link between nest survival and dominance rank.

Female chickadees mated to high-ranking males appeared to enjoy increased reproductive success. It does not appear that the costs of increased clutch size decrease the likelihood of survival of the parents (Smith 1984, 1994; Lemon et al. 1997). Thus, the increased number of young produced by females with high-ranking mates, their higher probability of fledging young, and their increased survival potential appear to increase the reproductive success of these females. Additionally, clutch size and survival of young to nedying appear to be more closely associated with the rank of the female's mate than with her own rank. Thus, females mated to low ranking males may contin uously seek opportunities to mate with highranking males in order to increase their reproductive success, even if this entails divorcing their current partner (Smith 1988, Ens et al. 1993, Dhondt and Adriaensen 1994, Otter and Ratcliffe 1996). If genetic quality of nestlings somehow enhances their survival ability (a topic that awaits future research), this may also explain female solicitation of extrapair copulations from high-ranking males (Smith 1988) in order to have these males sire some of the female's offspring (Otter et al. 1994, 1998).

\section{ACKNOWLEDGMENTS}

We thank C. McDonald, S. Rice, B. Chruszcz, C. James, S. Cosh, V. Muehter, A. Nirwal, W. McLeish, and T. Talvila for assistance in the field. C. Barber, A. A. Dhondt, P. T. Boag, P. Taylor, K. Wynne-Edwards, $S$. Haftorn, and two anonymous reviewers provided comments on earlier drafts of the manuscript. Logistic support was provided by the Queen's University Biological Station, and access to property was permitted by the Curtis, Weatherhead-Metz, Monaghan, Warren, and Lundell families. Funding was provided by donations from E. and I. Ramsay and PPC C anada, Ins, an A nimal Rehavior Award, a John K. Cooper Award, a Sigma Xi Grant-in-aid of Research, Society of Canadian Ornithologists' Taverner Awards, an Ontario Graduate Scholarship, and an NSERC operating grant.

\section{Literature Cited}

Albano, D. J. 1992. Nesting mortality of Carolina Chickadees breeding in natural cavities. Condor 94:371-382.
BRÖMSSEN, A. VON, AND C. JANSSON. 1980. Effects of food addition to Willow Tit Parus montanus and Crested Tit $P$. cristatus at the time of breeding. Ornis Scandinavica 11:173-178.

DESROCHERS, A. 1990. Sex determination of Blackcapped Chickadees with a discriminant analysis. Journal of Field Ornithology 61:79-84.

Dhuivdt, A. A., aind F. Adriaeinsen. 1994. Causes and effects of divorce in the Blue Tit Parus caeruleus. Journal of Animal Ecology 63:979-987.

Dhondt, A. A., F. Adriaensen, E. Matthysen, And B. Kempenaers. 1990. Nonadaptive clutch sizes in tits. Nature 348:723-725.

Dhondt, A. A., B. Kempenaers, AND F. Adriaensen. 1992. Density-dependent clutch size caused by habitat heterogeneity. Journal of Animal Ecology 61:643-648.

ENS, B. J., U. N. SAFriel, AND M. P. HARRIS. 1993. Divorce in the long-lived and monogamous Oystercatcher, Haematopus ostralegus: Incompatibility or choosing a better option? Animal Behaviour 45:1199-1217.

FICKEN, M. S., C. M. WeISE, AND J. W. Popp. 1990. Dominance rank and resource access in winter flochs of Dlach-capped Clichadees. Wilsun Dulletin 102:623-633.

GrubB, T. C., JR., AND C. L. BRONSON. 1995. Artificial snags as nesting sites for chickadees. Condor 97: 1067-1070.

Gustafsson, L., AND W. J. Sutherland. 1988. The cost of reproduction in the Collared Flycatcher ricedula albicollts. Nature $335: 813-813$.

HAFTORN, S. 1979. Incubation and regulation of egg temperature in the Willow Tit Parus montanus. Ornis Scandinavica 10:220-234.

HILL, G. E. 1991. Plumage colouration is a sexually selected indicator of male quality. Nature 350: 337-339.

HÖGSTEDT, G. 1980. Evolution of clutch size in birds: Adaptive variation in relation to territory quality. Science 210:1148-1150.

IIÜGSTEDT, G. 1981. Shuuld llete be a pusilive uI negative correlation between survival of adults in a bird population and their clutch size? American Naturalist 118:568-571.

KÄLLANDER, H. 1974. Advancement of laying of Great Tits by the provision of food. Ibis 116:365367.

KEMPENAERS, B., AND A. A. DHONDT. 1992. Experimental test of an hypothesis explaining density dependent clutch-size in tits Parus spp. Ibis 134: 192-194.

LACK, D. 1954. The natural regulation of animal numbers. Oxford University Press, Oxford.

LEMMON, D., M. L. WithiaM, AND C. P. L. BARKAN. 1997. Mate protection and winter pair-bonds in Black-capped Chickadees. Condor 99:424-433.

Meigs, J. B., D. C. SMith, AND J. V. BuskiRK. 1983. Age 
determination of Black-capped Chickadees. Journal of Field Ornithology 54:283-286.

Nur, N. 1984a. The consequences of brood size for breeding Blue Tits I. Adult survival, weight change and the cost of reproduction. Journal of Animal Ecology 53:479-496.

NuR, N. 1984b. The consequences of brood size for breeding Blue Tits II. Nestling weight, offspring survival and optimal brood size. Journal of Animal Ecology 53:497-517.

Nur, N. 1986. Is clutch sizc variation in the Bluc Tit (Parus caeruleus) adaptive? An experimental study. Journal of Animal Ecology 55:983-999.

NuR, N. 1988. The consequences of brood size for breeding Blue Tits III. Measuring the cost of reproduction: Survival, future fecundity, and differential dispersal. Evolution 42:351-362.

ORELL, M., AND K. KoIVULA. 1988. Cost ot reproduction: Parental survival and production of recruits in the Willow Tit Parus montanus. Oecolosia 77:123 132 .

Otter, K., B. Chruszcz, AND L. Ratcliffe. 1997. Honest advertisement and song output during the dawn chorus of Black-capped Chickadees. Behavioral Ecology 8:167-173.

OTTER, K., AND L. RATClifFe. 1996. Female initiated divorce in a monogamous songbird: Abandoning mates for higher quality males. Proceedings of the Royal Society of London Series B 26:351355.
Otter, K., L. Ratcliffe, AND P. T. Boag. 1994. Extrapair paternity in the Black-capped Chickadee. Condor 96:218-222.

Otter, K., L. Ratcliffe, D. Michaud, and P. T. BOAG. 1998. Do female Black-capped Chickadees prefer high-ranking males as extra-pair partners? Behavioral Ecology and Sociobiology 43:25-36.

Perrins, C. M., ANd D. Moss. 1975. Reproductive rates in the Great Tit. Journal of Animal Ecology 44:659-706.

SLAGSVOLD, T., AND J. LIFJELD. 1990. Influence of male and female quality on clutch size in tits ( $\mathrm{Pa}-$ rus spp.). Ecology 71:1258-1266.

SMITH, S. M. 1984. Flock switching in chickadees: Why be a winter floater? American Naturalist 123:81-98.

SMITH, S. M. 1988. Extra-pair copulations in Blackcapped Chickadees: The role of the female. Behaviour 107:15-23.

Smith, S. M. 1991. The Black-capped Chickadee: Behavioral ccology and natural history. Comstock Publishing, New York.

SMITH, S. M. 1994. Social influences on the dynamics of a northeastern Black-capped Chickadee population. Ecology 75:2043-2051.

TRIVERS, R. L. 1972. Parental investment and sexual selection. Pages 136-179 in Sexual selection and the decent of man (B. Campbell, Ed.). Aldine Publishing Company, Chicago.

Associate Editor: J. Ekman 